University of Nebraska - Lincoln

DigitalCommons@University of Nebraska - Lincoln

USDA National Wildlife Research Center - Staff

Publications
U.S. Department of Agriculture: Animal and Plant Health Inspection Service

$10-2010$

\title{
Shedding and serologic responses following primary and secondary inoculation of house sparrows (Passer domesticus) and European starlings (Sturnus vulgaris) with low-pathogenicity avian influenza virus
}

Nicole M. Nemeth

Colorado State University, nnemeth@colostate.edu

Nicholas 0. Thomas

USDA/APHIS/WS/National Wildlife Research Center

Darcy S. Orahood

USDA/APHIS/WS/National Wildlife Research Center

Theodore D. Anderson

USDA/APHIS/WS/National Wildlife Research Center

Paul T. Oesterle

University of Georgia, poester@uga.edu

Follow this and additional works at: https://digitalcommons.unl.edu/icwdm_usdanwrc

Nemeth, Nicole M.; Thomas, Nicholas O.; Orahood, Darcy S.; Anderson, Theodore D.; and Oesterle, Paul T., "Shedding and serologic responses following primary and secondary inoculation of house sparrows (Passer domesticus) and European starlings (Sturnus vulgaris) with low-pathogenicity avian influenza virus" (2010). USDA National Wildlife Research Center - Staff Publications. 1277.

https://digitalcommons.unl.edu/icwdm_usdanwrc/1277

This Article is brought to you for free and open access by the U.S. Department of Agriculture: Animal and Plant Health Inspection Service at DigitalCommons@University of Nebraska - Lincoln. It has been accepted for inclusion in USDA National Wildlife Research Center - Staff Publications by an authorized administrator of DigitalCommons@University of Nebraska - Lincoln. 


\title{
Shedding and serologic responses following primary and secondary inoculation of house sparrows (Passer domesticus) and European starlings (Sturnus vulgaris) with low-pathogenicity avian influenza virus
}

\author{
Nicole M. Nemeth*, Nicholas O. Thomas, Darcy S. Orahood, Theodore D. Anderson and \\ Paul T. Oesterle
}

USDA/APHIS/WS/National Wildlife Research Center, 4101 Laporte Avenue, Fort Collins, CO 80521, USA

\begin{abstract}
Waterfowl and shorebirds are well-recognized natural reservoirs of low-pathogenicity avian influenza viruses (LPAIV); however, little is known about the role of passerines in avian influenza virus ecology. Passerines are abundant, widespread, and commonly come into contact with free-ranging birds as well as captive game birds and poultry. We inoculated and subsequently challenged house sparrows (Passer domesticus) and European starlings (Sturnus vulgaris) with wild-bird origin LPAIV H3N8 to evaluate their potential role in transmission. Oropharyngeal shedding was short lived, and was detected in more starlings (97.2\%) than sparrows $(47.2 \% ; n=36$ of each). Cloacal shedding was rare in both species $(8.3 \% ; n=36$ of each) and no cage-mate transmission occurred. Infectious LPAIV was cultured from oropharyngeal and cloacal swabs and gastrointestinal and respiratory tissues from both species. Seroconversion was detected as early as 3 days post inoculation (d.p.i.) (16.7\% of sparrows and $0 \%$ of starlings; $n=6$ each); $50 \%$ of these individuals seroconverted by 5 d.p.i., and nearly all birds $(97 \% ; n=35)$ seroconverted by 28 d.p.i. In general, pre-existing homologous immunity led to reduced shedding and increased antibody levels within 7 days of challenge. Limited shedding and lack of cage-mate transmission suggest that passerines are not significant reservoirs of LPAIV, although species differences apparently exist. Passerines readily and consistently seroconverted to LPAIV, and therefore inclusion of passerines in epidemiological studies of influenza outbreaks in wildlife and domestic animals may provide further insight into the potential involvement of passerines in avian influenza virus transmission ecology.
\end{abstract}

\section{Introduction}

Avian influenza viruses (AIV) (family Orthomyxoviridae, genus Influenzavirus $A$ ) are an important cause of largescale economic losses in the poultry industry, as well as disease in humans (Spickler et al., 2008). Both lowpathogenicity avian influenza viruses (LPAIV) and highpathogenicity avian influenza viruses (HPAIV) are shed in the excrement of infected birds, and some AIV remain viable in water for relatively long periods of time (Stallknecht et al., 1990a; Brown et al., 2007). In particular, members of the order Anseriformes (i.e. ducks, swans, geese) and Charadriiformes (i.e. shore birds, gulls, terns) represent a significant reservoir of influenza A viruses in nature and are often the focus of research and surveillance (Webster et al., 1992; Olsen et al., 2006; Munster et al., 2007). However, additional free-ranging bird species may contribute to AIV transmission and maintenance in nature (Stallknecht \& Shane, 1988).

Some bird species within the order Passeriformes are ubiquitous and abundant throughout much of North America and often occupy a variety of habitats that overlap with both rural and residential areas. AIV, including some HPAIV, have been isolated or detected by reverse transcriptase-polymerase chain reaction (RTPCR) in samples originating from free-living passerines of at least 24 species, although these detections are relatively rare (Lipkind et al., 1979; Boudreault et al., 1980; Hinshaw \& Webster 1982; Roy et al., 1983; Nestorowicz et al., 1987; Mase et al., 2005; Peterson et al., 2008). Surveys in the USA, Canada, Egypt, Hungary, and Slovakia suggest that numerous freeranging passerines become infected with LPAIV, and therefore could potentially play a role in transmission and spread (Romváry et al., 1976, in Stallknecht \& Shane, 1988; Johnson et al., 1977; Amin et al., 1980; Boudreault et al., 1980; Al-Attar et al., 2008; Fuller et al., 2010). Numerous passerine species, such as the house sparrow (Passer domesticus) and European starling (Sturnus vulgaris), commonly intermingle with domestic game birds and poultry. For proper risk assessments to be made, a better understanding of the interface between wild and domestic birds and potential

*To whom correspondence should be addressed. Current address: Department of Pathology, College of Veterinary Medicine, University of Georgia, Athens GA 30602, USA. Tel: +1 706542 5837. Fax: +1 706542 5828. E-mail: nmnemeth@uga.edu

Received 28 April 2010

ISSN 0307-9457 (print)/ISSN 1465-3338 (online)/10/050411-08 (C) 2010 Houghton Trust Ltd

DOI: $10.1080 / 03079457.2010 .513043$ 
AIV transmission between these groups is needed (Olsen et al., 2006). Furthermore, knowledge of shedding and seroconversion among passerine birds is necessary to understand the potential for passerines to transmit AIV to domestic bird flocks and/or free-ranging birds.

The major objectives of the present study were to delineate the potential role of passerines in LPAIV transmission ecology based on experimental infections with a wild-bird-origin LPAIV H3N8 strain. More specifically, we examined susceptibility to infection, proportions and magnitude of oropharyngeal and cloacal shedding, bird-to-bird transmission, tissue tropism, seroconversion over time and following challenge inoculation, and subsequent protection provided by homologous anti-AIV antibodies. A subset of samples (i.e. swabs and tissues) was passaged in eggs to assess infectivity.

\section{Materials and Methods}

Bird capture and husbandry. Free-ranging European starlings (hereafter, starlings) were trapped in Moore County, Texas, USA in December 2008, and house sparrows (hereafter, sparrows) in Larimer County, Colorado, USA in January 2009. Both were transported by vehicle to the National Wildlife Research Center in Fort Collins, Colorado. Following arrival, birds were banded with numbered aluminium bands, bled via jugular venipuncture ( 0.1 to $0.2 \mathrm{ml}$ ), swabbed (oropharyngeal and cloacal cavities), and housed with four individuals per cage (starling cage dimensions, 36 inches long $\times 18$ inches wide $\times 18$ inches high; sparrow cage dimensions, 18 inches long $\times 18$ inches wide $\times 18$ inches high).

Birds were maintained in a biosafety level 2 facility on a 12-h light cycle at 60 to $65^{\circ} \mathrm{F}$ and ambient humidity (approximately 20 to $40 \%$ ). Starlings were fed Layena ${ }^{\circledR}$ Purina Mills ${ }^{\circledR}$ chicken feed while sparrows were fed a dry seed mix of millet, milo and sunflower ad libitum; all birds were provided with fresh water and sand grit. Birds underwent a quarantine and acclimation period of approximately 2 weeks prior to experimental inoculation. Capture, husbandry, and experimentation on birds was performed under Institutional Animal Care and Use Committee approval.

Virus inoculum. Birds in the present study were inoculated with LPAIV strain A/wild bird/California/08 (H3N8), a subtype that has been isolated from free-ranging waterfowl on multiple occasions (Stallknecht et al., 1990b; Slemons et al., 1991; Pasick et al., 2010). The H3N8 isolate used in the present study was isolated from a pool of five faecal samples originating from gadwall (Anas strepera), northern pintail (Anas acuta), and/or northern shoveler (Anas clypeata) collected on 28 October 2008 in Ventura County, California. The stock isolate was passaged once in 10-day-old specific pathogen free embryonated chicken eggs and diluted in BA-1 medium (M199-Hank's salts, 1\% bovine serum albumin, $350 \mathrm{mg} / \mathrm{l}$ sodium bicarbonate, 100 units $/ \mathrm{ml}$ penicillin, $100 \mu \mathrm{g} / \mathrm{ml}$ streptomycin, $2.5 \mu \mathrm{g} / \mathrm{ml}$ amphotericin $\mathrm{B}$ in $0.05 \mathrm{M}$ Tris, $\mathrm{pH}$ 7.6). One hundred microlitres of virus inoculum contained approximately $10^{6.0}$ median embryo equivalent infectious dose $\left(\mathrm{EID}_{50}\right)$ of LPAIV H3N8. Virus back titration and RT-PCR confirmed that the dose was between $10^{5.5}$ and $10^{6.5} \mathrm{EID}_{50}$.

Experimental design and bird inoculation. In total (i.e. phases one and two), 36 starlings and 36 sparrows naïve to AIV were inoculated via the ocular, nasal, and oropharyngeal routes with H3N8 LPAIV, administered as $15 \mu \mathrm{l}$ into the nares, $15 \mu \mathrm{l}$ into the eyes, and $70 \mu \mathrm{l}$ into the oropharyngeal cavity $(100 \mu$ total).

Phase one of the experiment consisted of LPAIV inoculation of 18 starlings and 18 sparrows; these birds were co-housed with shaminoculated conspecifics so that each cage housed two LPAIV-inoculated birds and two sham-inoculated birds per cage. Sham inoculation was by administration of allantoic fluid diluted in BA-1 medium using the same volume and routes as with AIV inoculation described above. Oropharyngeal swabs were collected from all birds 1 to 14 days post inoculation (d.p.i.). Cloacal swabs were collected daily from starlings from 1 to 14 d.p.i. and from sparrows at 1 to 8, 10, 12, and 14 d.p.i. In addition, all birds were bled just prior to initial inoculation and on 7, 14, 21, and 28 d.p.i.

Phase two of the experiment consisted of challenge (i.e. secondary) inoculation of birds that had been initially inoculated 28 days previously (i.e. 18 starlings and 17 sparrows due to the death of one sparrow during phase one), as well as initial LPAIV inoculation of previously shaminoculated cage mates. All birds in the latter group were confirmed negative for LPAIV shedding and antibodies after potential exposure via cage mates and again at the time of inoculation. The same strain, dose (again confirmed by back titration and RT-PCR as approximately $10^{6.0} \mathrm{EID}_{50}$ ), and route of inoculation was performed for both initial and challenge inoculations. Following challenge inoculation, oropharyngeal swabs were collected from 1 to 10 d.p.i., while cloacal swabs were collected from 1 to 10 d.p.i. for starlings, and 1 to 8 and 10 d.p.i. for sparrows. Birds were bled at 7 and 14 days post challenge and humanely killed at the latter time point by intravenous overdose of pentobarbital sodium and phenytoin sodium solution.

All birds undergoing initial inoculation during phase two (18 starlings and 18 sparrows), were swabbed daily until they were killed humanely on 3 , 4, or 5 d.p.i., at which time blood was also collected. Six individuals per species at each of these times points were killed humanely to evaluate for the presence of viral RNA (and in select samples, infectious AIV) in tissues, and to assess for seroconversion at these relatively early time points.

Tissue collection and processing. For birds killed during acute infection (3, 4, or 5 d.p.i.), the following tissues were collected and frozen to $-80^{\circ} \mathrm{C}$ : superior part of the duodenum, distal large colon, trachea, and left lung.

Prior to testing by RT-PCR, tissues were thawed, ground in a mixer mill (Retsch GmbH, Haan, Germany) at 20 cycles/second for $4 \mathrm{~min}$ (blocks were rotated at $2 \mathrm{~min}$ ), and centrifuged at $10,000 \mathrm{x} g$ for $3 \mathrm{~min}$. Tissue supernatants were processed using a Qiagen MagAttract Viral RNA M48 Kit according to manufacturer's instructions with a bead mill (Qiagen Inc., Valencia, California, USA)

Viral gene detection. Quantitative real-time RT-PCR targeting the AIV matrix gene (Spackman et al., 2002) was used to detect AIV in swab samples and tissue supernatants. Inoculated birds with oropharyngeal shedding limited to 1 d.p.i. were not considered to have shed virus via this route because of probable residual inoculum in the oral cavity at this early time point. All samples were assayed in duplicate and a standard curve was calculated from three or more samples with known quantities of virus with $R^{2} \geq 0.99$. Quantities and cycle threshold $(\mathrm{Ct})$ values were calculated and the former were used to analyse shedding profiles. The minimum threshold for detection of AIV from swab and tissue supernatants via RT-PCR was a mean quantity of $10.0 \mathrm{EID}_{50}$ equivalents (corresponding to a $\mathrm{Ct}$ value of approximately 38 ).

Virus isolation. A subset of RT-PCR-positive samples with EID $_{50}$ equivalent quantities $\geq 10^{2}$, including both oropharyngeal and cloacal swabs and at least two tissue supernatants from each species, was inoculated into embryonated chicken eggs using standard methods (Woolcock, 2008). Prior to virus isolation testing, samples were stored at $-80^{\circ} \mathrm{C}$ and underwent two freeze-thaw cycles. Briefly, each sample was serially diluted 10 -fold in TBTB $+33 \mathrm{~T}$ antibiotics, and $100 \mu \mathrm{l}$ of each dilution was inoculated into the chorioallantoic sac of five 9-dayold specific pathogen free chicken eggs. For each assay, TBTB + 33T antibiotics were used as a negative control and $\mathrm{H} 3 \mathrm{~N} 8$ virus stock as a positive control (five eggs each). Amnio-allantoic fluid was collected from embryos that died between 24 and $120 \mathrm{~h}$ post inoculation and tested for the presence of haemagglutinin protein. Haemagglutination assays were performed in round-bottom, 96-well plates with amnioallantoic fluid serially diluted in phosphate-buffered saline and $0.5 \%$ chicken erythrocyte solution. The Reed-Müench method was used for calculating EID $_{50}$ values (Reed \& Müench, 1938).

Serology. Prior to testing, sera were frozen at $-80^{\circ} \mathrm{C}$ and thawed once, and then heat inactivated at $56^{\circ} \mathrm{C}$ for $30 \mathrm{~min}$. A previously developed 
blocking enzyme-linked immunosorbent assay (ELISA) for antibodies to AIV was used to detect and quantify antibodies in bird sera (Sullivan et al., 2009). Each serum sample was run in duplicate and samples with mean percentage inhibition $\geq 32 \%$ were considered antibody-positive.

Data analyses. Average daily shedding for each species was calculated using the full set of RT-PCR data (including quantities $<10$ ), and average duration of shedding included periods of intermittent shedding (i.e. when days with undetectable shedding were preceded and followed by detectable shedding).

The Proc Mixed procedure (SAS Institute, Cary, North Carolina, USA) with repeated measures was used for data analysis, and Akaike's information criteria (AIC) with bias correction for small sample sizes (AICc) were used for model selection (Burnham \& Anderson, 2002). The latter method tested which sets of factors best predicted the two dependent variables of oropharyngeal shedding and antibody responses. Nineteen models were used to predict RT-PCR quantities of LPAIV viral RNA in oropharyngeal swabs and to predict ELISA percentage inhibition (representing antibody responses). Both RT-PCR quantities and ELISA percentage inhibition (serving as the dependent variables) were analysed as a function of three fixed variables: d.p.i., species, and inoculation sequence (i.e. initial versus challenge). The two model sets contained no effects models (intercept only with dependent variable independent of all fixed variables included within the model set), singleeffects models (species, d.p.i., or inoculation sequence) and several additive and interactive models, one of which was a fully interactive model. Individual AIC weights were calculated for each model. Cloacal shedding yielded very few positive data points and therefore was not analysed.

\section{Results}

Oropharyngeal and cloacal shedding. Prior to inoculation, all birds were negative for oropharyngeal and cloacal shedding of AIV by RT-PCR. Following LPAIV H3N8 inoculation of 72 birds (36 sparrows and 36 starlings, including both phases one and two), more starlings $(35 / 36 ; 97.2 \%)$ than sparrows $(19 / 36 ; 52.8 \%)$ shed via the oropharyngeal cavity as determined by RTPCR (Figure 1). Oropharyngeal shedding occurred between 1 and 5 d.p.i. in both species, and the average duration of shedding after initial inoculation of starlings was 3.3 days $(n=36,95 \%$ confidence interval $[\mathrm{CI}]=$ $3.18,3.82)$, while sparrows shed for an average of 1.5 days $(n=36,95 \% \mathrm{CI}=0.95,2.05)$. Few individuals had detectable cloacal shedding by quantitative RTPCR; 3/36 (8.3\%) individuals of each species had

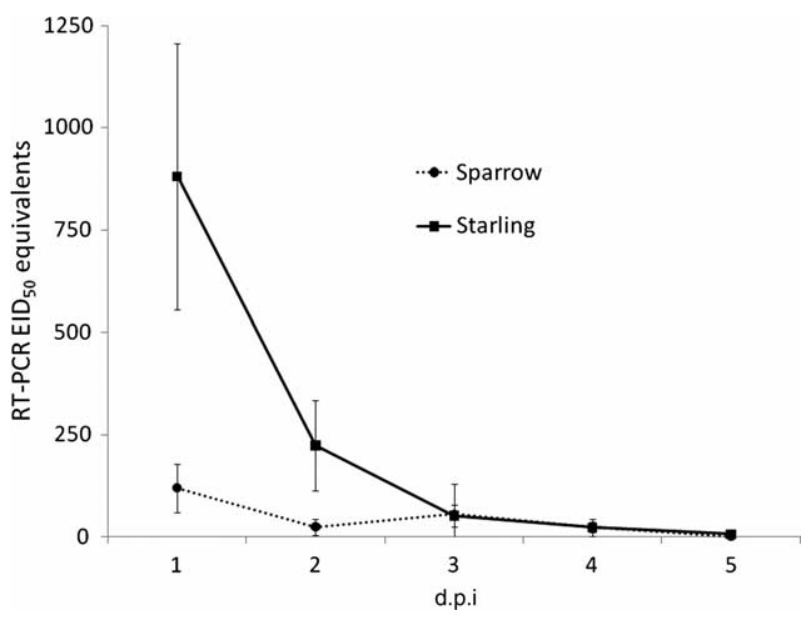

Figure 1. Mean quantities of oropharyngeal LPAIV shedding in house sparrows and European starlings following experimental inoculation (error bars represent 95\% confidence intervals). positive cloacal swabs (quantities 11.2 to 152.0) between 1 and 5 d.p.i., and duration of cloacal shedding was usually 1 day, although one sparrow shed for 3 consecutive days. Influenza A virus was isolated from oropharyngeal swabs from sparrows and starlings ( 2 to 4 d.p.i.) and a cloacal swab from a sparrow (5 d.p.i.; Table 1). RT-PCR-positive swab samples from which LPAIV isolation was unsuccessful included an oropharyngeal swab from a sparrow ( 2 d.p.i.) and a cloacal swab from a starling (3 d.p.i.).

Following challenge inoculation of 17 sparrows and 18 starlings 28 days post initial inoculation, 4/17 (23.5\%) sparrows and 6/18 (33.3\%) starlings had detectable oropharyngeal shedding. Oropharyngeal shedding percentages were lower following challenge inoculation versus initial inoculation. Similarly, oropharyngeal and cloacal shedding duration and quantities were lower following challenge inoculation versus initial inoculation. As for initial inoculation, cloacal shedding after challenge inoculation was rare with only $1 / 17(5.9 \%)$ sparrows and $1 / 18(5.6 \%)$ starlings with detectable shedding, both on 3 d.p.i. (RT-PCR quantities of 11.5 and 17, respectively; Table 1). The average duration of oropharyngeal shedding after challenge inoculation was 0.8 days for sparrows $(n=17,95 \% \mathrm{CI}=0.08,1.45)$ and 1 day for starlings $(n=18,95 \% \mathrm{CI}=0.09,1.91)$.

Quantities of LPAIV shed via the oropharyngeal cavity were influenced by species, d.p.i., and inoculation sequence (i.e. initial versus challenge). Based on AICc, the model that best fit the data was fully interactive, including all of the effects of the fixed variables (species, d.p.i., and inoculation sequence). This model was heavily weighted (Akaike weight $=1.000$ ) and indicated that species, d.p.i., and inoculation sequence affected RTPCR quantities of oropharyngeal shedding (Table 2).

Clinical observations. No clinical illness was observed during the study, although one inoculated sparrow died on 14 d.p.i. following blood collection.

Cage-mate transmission. No cage-mate transmission was detected in either species, as all non-inoculated cage mates remained seronegative and were negative for oropharyngeal and cloacal shedding throughout the 28 days that they were co-housed with inoculated conspecifics (i.e. for $>3$ weeks beyond detectable shedding in the inoculated cage mates).

Tissue tropism. For birds killed between 3 and 5 d.p.i., 8/ $18(44.4 \%)$ of the sparrows and of the starlings had at least one RT-PCR-positive tissue (trachea, lung, small intestine, and/or large intestine; Table 3). Trachea and duodenum were the most commonly positive tissues among sparrows $(4 / 18 ; 22.2 \%)$ and starlings (5/18; $27.8 \%$ ), respectively. Influenza A virus was isolated from homogenized trachea, lung, and large intestine collected between 3 and 5 d.p.i. from starlings and sparrows. Samples that were RT-PCR-positive but from which LPAIV isolation failed included sparrow duodenum (3 d.p.i.) and starling large intestine (4 d.p.i.), trachea (5 d.p.i.), and duodenum (5 d.p.i.).

Serology. Upon capture, all birds were negative for antibodies to internal proteins of AIV. Following initial inoculation, early antibody responses (i.e. 3 to 5 d.p.i.) 
Table 1. Oropharyngeal and cloacal shedding determined by RT-PCR in two passerine species following initial and challenge inoculation with LPAIV.

\begin{tabular}{|c|c|c|c|c|c|}
\hline \multirow[b]{2}{*}{ Species } & \multirow[b]{2}{*}{$\begin{array}{l}\text { Swab } \\
\text { sample }\end{array}$} & \multicolumn{2}{|c|}{ Initial inoculation } & \multicolumn{2}{|c|}{ Post-challenge inoculation } \\
\hline & & $\begin{array}{c}\text { Proportion positive } \\
(\%)\end{array}$ & $\begin{array}{l}\text { Mean duration of shedding d.p.i. } \\
\text { (range) }\end{array}$ & $\begin{array}{l}\text { Proportion positive } \\
\qquad(\%)\end{array}$ & $\begin{array}{l}\text { Mean duration of shedding d.p.i. } \\
\text { (range) }\end{array}$ \\
\hline HOSP & $\mathrm{ORO}^{\mathrm{a}}$ & $19 / 36(52.8 \%)$ & $1.50(1-4)$ & $4 / 17(23.5 \%)$ & $0.76(1-4)$ \\
\hline EUST & ORO & $35 / 36(97.2 \%)$ & $3.31(1-5)$ & $6 / 18(33.3 \%)$ & $1.00(1-4)$ \\
\hline HOSP & CLO & $3 / 36(8.3 \%)$ & $0.14(1-5)$ & $1 / 17(5.9 \%)$ & $0.06(3)$ \\
\hline EUST & CLO & $3 / 36(8.3 \%)$ & $0.08(1-5)$ & $1 / 18(5.6 \%)$ & $0.06(3)$ \\
\hline
\end{tabular}

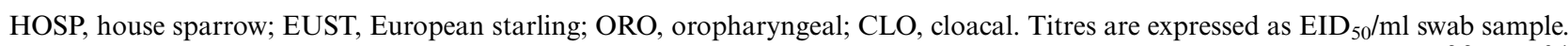
${ }^{a}$ Virus isolation-positive samples from sparrows included oropharyngeal swabs from three individuals on 3 to 4 d.p.i. $\left(10^{2.2}\right.$ to $10^{3.1}$ $\left.\mathrm{EID}_{50} / \mathrm{ml}\right)$ and a cloacal swab on 5 d.p.i. $\left(10^{4.3} \mathrm{EID}_{50} / \mathrm{ml}\right)$; and from starlings included oropharyngeal swabs from six individuals on 2 to 4 d.p.i. $\left(10^{2.2}\right.$ to $\left.10^{3.4} \mathrm{EID}_{50} / \mathrm{ml}\right)$.

were detected in 5/18 (27.8\%) sparrows and 4/18 (22.2\%) starlings. By 7 d.p.i., 14/18 (77.8\%) each of sparrows and starlings had evidence of antibodies to LPAIV H3N8. These percentages subsequently increased, and by 28 d.p.i. all sparrows $(17 / 17 ; 100 \%)$ and all but one starling $(17 / 18 ; 94.4 \%)$ were antibody-positive (Figure 2). The single starling that failed to shed or seroconvert following initial inoculation subsequently shed and seroconverted following challenge inoculation, so the initial inoculation attempt of this bird was probably unsuccessful.

On the day of challenge inoculation (i.e. 28 days following initial inoculation), 17/17 sparrows and 17/18 starlings were LPAIV seropositive with percentage inhibition values from 37 to $99 \%$ for starlings, and from 33 to $88 \%$ for sparrows. By 7 days post-challenge, $11 / 18(61.1 \%)$ starlings had $\geq 10 \%$ increase in percentage inhibition (range of increase 1 to $31 \%$; average increase $12 \%$; none decreased). Likewise, the majority of sparrows $(12 / 17 ; 70.6 \%)$ had $\geq 10 \%$ increase in percentage inhibition by 7 days post-challenge (range 2 to $48 \%$; average $22 \%$, excluding one individual with a $12 \%$ decrease). Percentage inhibition values were similar on 7 and 14 days post challenge in both starlings and sparrows (Figure 3).

Based on AICc, a fully interactive model that included all of the effects of the fixed variables (i.e. species, d.p.i. and inoculation sequence) best fit the data. This model was heavily weighted (Akaike weight $=1.000$ ) and indicated that species, d.p.i. and inoculation sequence influenced antibody responses (Table 4).

\section{Discussion}

The complex ecology of AIV has direct impacts on both human and animal health, and these impacts are dynamic and often unpredictable. Therefore, it is necessary to evaluate a wide spectrum of species for potential

Table 2. Model set testing the relationship between RT-PCR quantities representing LPAIV oropharyngeal shedding as the dependent variable and d.p.i., species and inoculation sequence as fixed variables in house sparrows and European starlings experimentally inoculated with LPAIV.

\begin{tabular}{|c|c|c|c|c|c|}
\hline \multirow[b]{2}{*}{ Model } & \multirow[b]{2}{*}{$K$} & \multicolumn{4}{|c|}{ Oropharygneal shedding } \\
\hline & & $-2 \log L$ & AICc & $\triangle \mathrm{AICc}$ & AIC weight \\
\hline Intercept only & 3 & $14,436.9$ & $14,442.9$ & 415.52 & 0.000 \\
\hline SP & 4 & $14,420.2$ & $14,428.2$ & 400.84 & 0.000 \\
\hline d.p.i. & 16 & $14,215.8$ & $14,248.3$ & 220.94 & 0.000 \\
\hline Inoc (initial or challenge) & 4 & $14,423.7$ & $14,431.7$ & 404.34 & 0.000 \\
\hline $\mathrm{SP}+$ d.p.i. & 17 & $14,195.4$ & $14,230.0$ & 202.61 & 0.000 \\
\hline SP*d.p.i. & 30 & $14,051.4$ & $14,113.3$ & 85.88 & 0.000 \\
\hline $\mathrm{SP}+\mathrm{Inoc}$ & 5 & $14,405.3$ & $14,415.4$ & 387.96 & 0.000 \\
\hline SP*Inoc & 6 & $14,397.1$ & $14,409.2$ & 381.78 & 0.000 \\
\hline d.p.i. + Inoc & 17 & $14,202.5$ & $14,237.1$ & 209.71 & 0.000 \\
\hline d.p.i. $*$ Inoc & 27 & $14,155.7$ & $14,211.2$ & 183.82 & 0.000 \\
\hline $\mathrm{SP}+$ d.p.i. + Inoc & 18 & $14,181.3$ & $14,218.0$ & 190.58 & 0.000 \\
\hline $\mathrm{SP}+$ d.p.i. $+\mathrm{Inoc}+\mathrm{SP} *$ d.p.i. & 31 & $14,035.2$ & $14,099.2$ & 71.81 & 0.000 \\
\hline $\mathrm{SP}+$ d.p.i. + Inoc $+\mathrm{SP} * \operatorname{Inoc}$ & 19 & $14,171.2$ & $14,210.0$ & 182.56 & 0.000 \\
\hline SP+d.p.i. + Inoc + d.p.i. ${ }^{*} \operatorname{Inoc}$ & 28 & $14,134.0$ & $14,191.6$ & 164.24 & 0.000 \\
\hline $\mathrm{SP}+$ d.p.i. $+\mathrm{Inoc}+\mathrm{SP} *$ d.p.i. $+\mathrm{SP} * \mathrm{Inoc}$ & 31 & $14,025.5$ & $14,089.5$ & 62.11 & 0.000 \\
\hline $\mathrm{SP}+$ d.p.i. + Inoc + SP*d.p.i. + d.p.i. ${ }^{*} \operatorname{Inoc}$ & 41 & $13,977.5$ & $14,063.0$ & 35.62 & 0.000 \\
\hline SP+d.p.i. + Inoc + SP*Inoc + d.p.i. $*$ Inoc & 29 & $14,123.4$ & $14,183.2$ & 155.76 & 0.000 \\
\hline $\mathrm{SP}+$ d.p.i. $+\operatorname{Inoc}+\mathrm{SP} *$ d.p.i. $+\mathrm{SP} * \operatorname{Inoc}+$ d.p.i. $* \operatorname{Inoc}$ & 42 & $13,967.2$ & $14,054.9$ & 27.50 & 0.000 \\
\hline $\begin{array}{l}\text { SP + d.p.i. }+ \text { Inoc }+ \text { SP*d.p.i. }+ \text { SP*Inoc }+ \text { d.p.i. } * \text { Inoc } \\
\text { SP*d.p.i. } * \text { Inoc }\end{array}$ & 52 & $13,917.7$ & $14,027.4$ & 0.00 & 1.000 \\
\hline
\end{tabular}

$K$, number of parameters; AICc, Akaike's information criteria with small sample size correction factor; $\triangle$ AICc, standardized AICc values (most supported model $=0$ ); AIC weight, weight of evidence for each model (most supported model in bold); SP, species; Inoc, inoculation sequence. 
Table 3. Tissue tropism determined by RT-PCR in two passerine species following primary inoculation with LPAIV.

\begin{tabular}{lcllll}
\hline Species & d.p.i. ${ }^{\mathrm{a}}$ & \multicolumn{1}{c}{ Trachea $^{\mathrm{b}}$} & \multicolumn{1}{c}{ Lung } & $\begin{array}{c}\text { Small } \\
\text { intestine }\end{array}$ & $\begin{array}{c}\text { Large } \\
\text { intestine }\end{array}$ \\
\hline HOSP $^{\mathrm{c}}$ & 3 & $1(16.7 \%)$ & $1(16.7 \%)$ & $1(16.7 \%)$ & $2(33.3 \%)$ \\
HOSP & 4 & $2(33.3 \%)$ & $1(16.7 \%)$ & $0(0 \%)$ & $1(16.7 \%)$ \\
HOSP & 5 & $1(16.7 \%)$ & $0(0 \%)$ & $1(16.7 \%)$ & $0(0 \%)$ \\
EUST & 3 & $0(0 \%)$ & $0(0 \%)$ & $1(16.7 \%)$ & $1(16.7 \%)$ \\
EUST & 4 & $0(0 \%)$ & $0(0 \%)$ & $2(33.3 \%)$ & $2(33.3 \%)$ \\
EUST $^{\text {d }}$ & 5 & $1(16.7 \%)$ & $1(16.7 \%)$ & $2(33.3 \%)$ & $0(0 \%)$ \\
\hline
\end{tabular}

HOSP, house sparrow; EUST, European starling.

${ }^{\text {a }}$ Six birds of each species were tested at each time point.

${ }^{\mathrm{b}}$ Virus isolation-positive samples from HOSP included the trachea $\left(10^{9.0} \mathrm{EID}_{50} / \mathrm{g}\right)$ and large intestine $\left(10^{5.1} \mathrm{EID}_{50} / \mathrm{g}\right)$ at 3 d.p.i. and the lung at 4 d.p.i. $\left(10^{4.7} \mathrm{EID}_{50} / \mathrm{g}\right)$, as well as lung from EUST at 5 d.p.i. $\left(10^{5.0} \mathrm{EID}_{50} / \mathrm{g}\right)$. Titres are expressed as EID $_{50} / \mathrm{g}$ tissue.

${ }^{c}$ Positive trachea and large intestine were from the same individual sparrow.

${ }^{\mathrm{d}}$ Positive trachea and lung were from the same individual starling.

involvement in virus transmission and maintenance, as well as for susceptibility to disease. Further, it is important to evaluate the consequences of infection with AIV strains originating from both poultry and wild birds. The present study examines whether free-ranging passerines are susceptible to infection with a wild-birdorigin LPAIV, and their potential subsequent role in dissemination of these viruses to other free-ranging or domestic birds, including poultry. While the majority of LPAIV isolates from free-ranging birds have originated from waterfowl (Stallknecht \& Shane, 1988), both LPAIV and HPAIV have been isolated from passerine birds throughout a wide geographic area encompassing portions of Europe, Australia, North America, Africa, Asia, and the Middle East. Examples of these isolations have included swabs collected from house sparrows in Hungary and European starlings in Israel and Australia (Romváry et al., 1976, in Stallknecht \& Shane, 1988; Lipkind et al., 1979; Amin et al., 1980; Boudreault et al., 1980; Boudreault \& LeComte, 1981; Cross, 1986; Nestorowicz et al., 1987; Kwon et al., 2005; Gronesova et al., 2008; Desvaux et al., 2009). In addition, cloacal

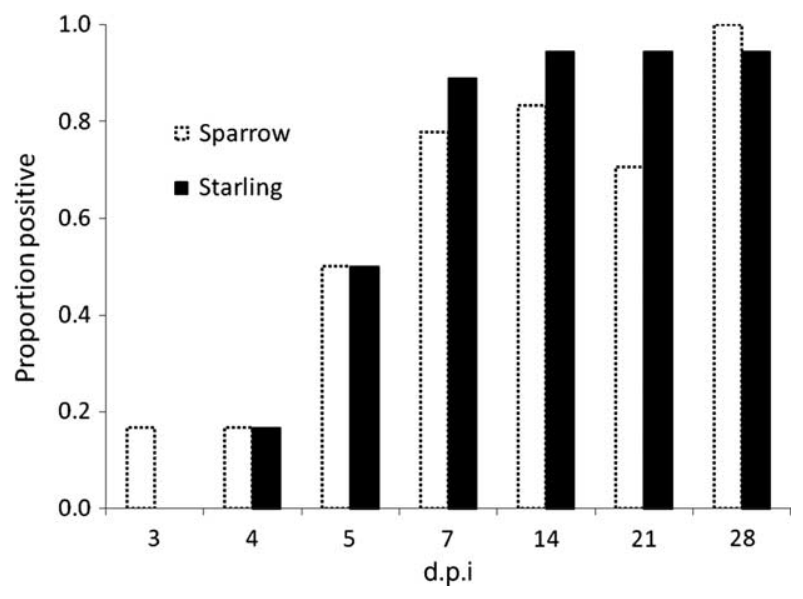

Figure 2. Timing and proportion of seroconversion in house sparrows and European starlings following experimental inoculation with LPAIV.

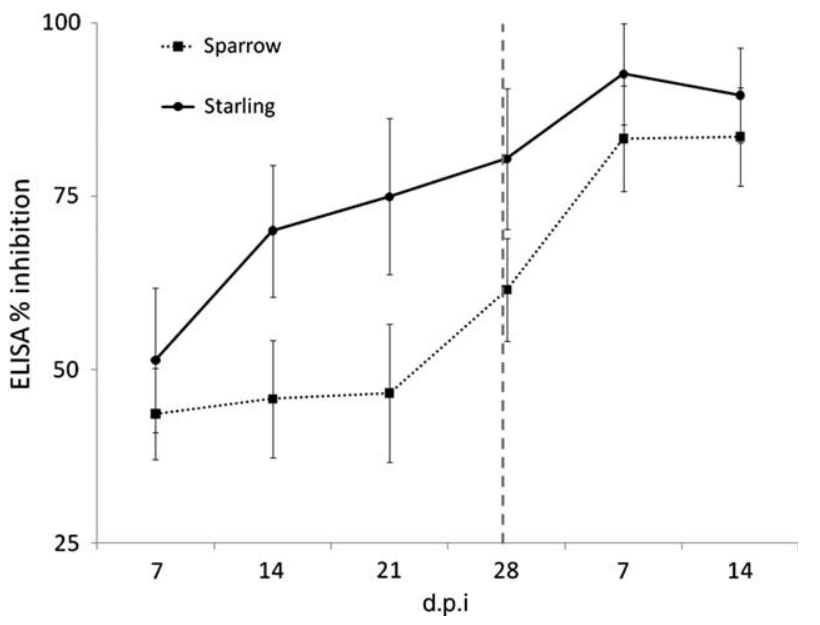

Figure 3. Seroconversion over time and serological responses to challenge in house sparrows and European starlings following experimental inoculation with LPAIV (error bars represent 95\% confidence intervals; dashed line at 28 days post-initial inoculation depicts timing of challenge inoculation).

swabs collected from 22 passerine species throughout the USA from 2005 to 2008 were AIV-positive by RT-PCR, with an approximate prevalence of $1 \%$ among passerines (Fuller et al., 2010).

European starlings and house sparrows are well established across North America, with starling numbers estimated at $>200$ million (Feare, 1984) and sparrows at approximately 150 million (Wing, 1943). These peridomestic, free-living passerines have frequent contact with other wild birds as well as domestic poultry and game birds (Stallknecht \& Shane, 1988), thereby creating opportunities for pathogen transmission. Shared food, substrate, and water sources probably involve crossspecies virus exposure originating from faeces, oropharyngeal secretions and possibly aerosolized droplets. Epidemiological studies have implicated poultry in the transmission of LPAIV to free-ranging birds, and vice versa (Cross, 1986; Nestorowicz et al., 1987). Repeated LPAIV infections of multiple host species as well as same-host co-infections that may result from this close relationship between domestic and free-ranging birds could increase the exchange of viral genetic material, and therefore the likelihood of increasingly virulent reassortant viruses (Campitelli et al., 2008; Moon et al., 2010).

The susceptibility of both house sparrows and European starlings to intranasal, oropharyngeal and ocular inoculation with wild-bird-origin LPAIV in the present study suggests that these birds could become infected through contact with actively shedding waterfowl. These results also suggest that both species may be capable of transmitting LPAIV through respiratory and oropharyngeal secretions, although no intraspecific bird-to-bird transmission occurred despite sustained direct contact between naïve birds and actively shedding cage mates. Starlings may have a greater potential to transmit LPAIV than sparrows based on a relatively higher frequency of individuals with oropharyngeal shedding and greater quantities of shedding of longer duration (Figure 1). Waterborne AIV transmission has been demonstrated via controlled studies in which house sparrows became infected with HPAIV H5N1 after 
Table 4. Model set testing the relationship between percentage inhibition representing anti-LPAIV antibodies as the dependent variable, and species and inoculation sequence as fixed variables in house sparrows and European starlings experimentally inoculated with LPAIV.

\begin{tabular}{|c|c|c|c|c|c|}
\hline Model & $K$ & $-2 \log L$ & $\mathrm{AICc}$ & $\triangle \mathrm{AICc}$ & AIC weight \\
\hline Intercept only & 3 & 2298.8 & 2304.9 & 301.17 & 0.000 \\
\hline SP & 4 & 2293.5 & 2301.7 & 297.93 & 0.000 \\
\hline d.p.i. & 9 & 2209.2 & 2228.0 & 224.22 & 0.000 \\
\hline Inoc (initial or challenge) & 4 & 2146.8 & 2155.0 & 151.23 & 0.000 \\
\hline SP + d.p.i. & 10 & 2201.5 & 2222.4 & 218.69 & 0.000 \\
\hline SP*d.p.i. & 15 & 2188.9 & 2221.0 & 217.24 & 0.000 \\
\hline $\mathrm{SP}+\mathrm{Inoc}$ & 5 & 2146.3 & 2156.5 & 152.81 & 0.000 \\
\hline SP*Inoc & 6 & 2136.7 & 2149.0 & 145.32 & 0.000 \\
\hline d.p.i. + Inoc & 10 & 2030.3 & 2051.2 & 47.49 & 0.000 \\
\hline d.p.i. ${ }^{*}$ Inoc & 11 & 2016.7 & 2039.8 & 36.09 & 0.000 \\
\hline $\mathrm{SP}+$ d.p.i. + Inoc & 11 & 2024.5 & 2047.6 & 43.89 & 0.000 \\
\hline SP + d.p.i. + Inoc +SP*d.p.i. & 16 & 1999.0 & 2033.4 & 29.62 & 0.000 \\
\hline SP + d.p.i. + Inoc + SP*Inoc & 12 & 2011.4 & 2036.7 & 32.99 & 0.000 \\
\hline $\mathrm{SP}+$ d.p.i. + Inoc + d.p.i. $*$ Inoc & 12 & 2011.0 & 2036.3 & 32.59 & 0.000 \\
\hline $\mathrm{SP}+$ d.p.i. + Inoc + SP*d.p.i. + SP*Inoc & 17 & 1990.3 & 2027.0 & 23.23 & 0.000 \\
\hline $\mathrm{SP}+$ d.p.i. + Inoc + SP*d.p.i. + d.p.i. $*$ Inoc & 17 & 1983.7 & 2020.4 & 16.63 & 0.000 \\
\hline $\mathrm{SP}+$ d.p.i. + Inoc + SP*Inoc + d.p.i. ${ }^{*} \operatorname{Inoc}$ & 13 & 1996.7 & 2024.3 & 20.52 & 0.000 \\
\hline $\mathrm{SP}+$ d.p.i. $+\operatorname{Inoc}+\mathrm{SP} *$ d.p.i. + SP*Inoc + d.p.i. ${ }^{*} \operatorname{Inoc}$ & 18 & 1974.2 & 2013.2 & 9.45 & 0.000 \\
\hline $\begin{array}{l}\mathrm{SP}+\text { d.p.i. }+ \text { Inoc }+ \text { SP*d.p.i. }+ \text { SP*Inoc }+ \text { d.p.i. }{ }^{*} \operatorname{Inoc} \\
\text { SP*d.p.i. }{ }^{*} \text { Inoc }\end{array}$ & 19 & 1962.4 & 2003.7 & 0.00 & 1.000 \\
\hline
\end{tabular}

$K$, number of parameters; AICc, Akaike's information criteria with small sample size correction factor; $\triangle \mathrm{AICc}$, standardized AICc values (most supported model =0); AIC weight, weight of evidence for each model (most supported model in bold); SP, species; Inoc, inoculation sequence.

being provided with water from cages of acutely infected chickens (Forrest et al., 2010). In contrast to oropharyngeal shedding, cloacal shedding of LPAIV H3N8 among sparrows and starlings was minimal. This could be due to differing pathogenesis in passerines versus ducks or chickens, in which cloacal shedding appears to be more common than oropharyngeal shedding ( $\mathrm{Lu} \&$ Castro, 2004; Mundt et al., 2009; Jourdain et al., 2010). Additionally, the proportion, magnitude, and duration of shedding in passerines was much less than has been observed in ducks, in which cloacal or faecal shedding has been detected for up to 21 or 22 d.p.i. (Alexander et al., 1978; Kida et al., 1980).

Serologic responses following LPAIV infection vary by host species and depend upon the origin, dose and subtype of the infecting virus (Kida et al., 1980; Lu \& Castro, 2004; Mundt et al., 2009); also, detection of antibodies varies by assay (Spackman et al., 2009; Sullivan et al., 2009). Antibody detection following AIV experimental inoculation of chickens, ducks, and passerines has been variable, sometimes with a transitory or lack of detectable humoral immune response (van der Goot et al., 2003; Al-Attar et al., 2008; Fereidouni et al., 2010). For example, seroprevalence among mallards (Anas platyrhynchos) that had been experimentally inoculated with LPAIV decreased from approximately 90 to $65 \%$ between 14 and 21 d.p.i., as determined by a commercially available ELISA (Spackman et al. 2009). In contrast, a recent study indicated that naturallyacquired antibodies to LPAIV persisted in mallards for up to 9 to 12 months (Fereidouni et al., 2010). Antibodies to AIV have been detected in free-ranging passerines, including house sparrows in the vicinity of an AIV outbreak in poultry (Nestorowicz et al., 1987). In the present study, nearly all birds seroconverted within 7 days of inoculation and antibody levels remained relatively constant over 4 weeks. These results suggest that passerines could be useful in serosurveillance for recent AIV activity.

The extent of protective LPAIV immunity in birds may alter the duration and intensity of seasonal transmission. Additional factors that may affect varying susceptibilities and subsequent responses to LPAIV infection include age and taxonomic differences (Costa et al., 2010). Evidence of protective immunity in waterfowl has been documented through observations in wild birds, as well as through controlled studies. In Sweden, multiple captures of migrating mallards revealed decreasing LPAIV shedding duration throughout the migration season, suggesting protective, possibly transient, immunity (Latorre-Margalef et al., 2009). In Germany, approximately 350 swans, geese and other birds suffered from HPAIV H5N1-associated morbidity and mortality while several hundred thousand coexisting conspecifics appeared healthy, supporting potential cross-protective immunity from previous AIV infection in the latter (Globig et al., 2009). Indeed, respiratory and intestinal shedding was reduced in mallards with preexisting homosubtypic or heterosubtypic immunity to LPAIV following challenge with HPAIV H5N1 or LPAIV subtypes (Fereidouni et al., 2009; Jourdain et al., 2010). These studies demonstrated short-term immune protection against re-infection in mallards (e.g. 3 to 7 weeks) that could lead to temporary herd immunity, thereby dampening intra-seasonal transmission. Similarly, the present study demonstrated homosubtypic immune protection of several passerines, evidenced by reduced quantities and duration of shedding as well as increased antibody levels 1 to 2 weeks after challenge. Long-term (i.e. inter-seasonal or interannual) LPAIV immunity among birds has been less well documented, although one study indicated that immunity may be relatively short lived ( $\leq 46$ days) in Pekin ducks (Anas platyrhynchos domesticus; Kida et al., 1980). Along with dampening transmission, cross-protective 
immunity in birds may decrease the likelihood of withinhost virus recombination of multiple subtypes, thereby diminishing the potential for virulence shifts.

Tissue tropism of LPAIV, which also appears to vary taxonomically among birds, provides insight into pathogenesis and may have implications for environmental transmission. Despite possible loss of sensitivity due to multiple freeze-thaw cycles prior to testing in the present study, AIV-positive swabs (by RT-PCR and/or virus isolation) collected from starlings and sparrows from 1 to 5 d.p.i. and respiratory and gastrointestinal tissues from 3 to 5 d.p.i. support infection of multiple systems. Ellström et al. (2009) demonstrated evidence for $\alpha 2,6$ linked sialic acids on receptors in the tracheal epithelium of nine avian species (including species within the orders Anseriformes, Galliformes, Charadriiformes, and Columbiformes), despite AIV isolates from birds most often preferentially binding to $\alpha 2,3$-linked sialic acids in the intestinal epithelium. However, the study did not include passerines. In past studies, virus was recovered from respiratory and gastrointestinal tissues of LPAIV experimentally inoculated passerines (including sparrows) and mallards from 2 to 7 d.p.i. (Roy et al., 1983; Tang et al., 2009), and infectious HPAIV (H7N7) was detected in both respiratory and gastrointestinal tissues of experimentally inoculated starlings and sparrows from 2 to 3 d.p.i. (Nestorowicz et al., 1987). While a cloacal swab and large intestine tissue from two house sparrows were positive for infectious AIV in the present study, oropharyngeal swabs and respiratory tissues were more commonly positive in both sparrows and starlings, suggesting that the respiratory system may be more predominantly involved in LPAIV infection than the gastrointestinal system in these species. Because ingestion of infected bird carcasses or contaminated faeces by chickens seems a more likely transmission mechanism than inhalation of infectious respiratory droplets, the relatively low levels of shedding and virus in tissues among sparrows and starlings in the present study suggest that sparrow-to-chicken LPAIV transmission may be a relatively unlikely event.

In conclusion, the results from the present study do not strongly support the involvement of two common and abundant passerine species in LPAIV maintenance and transmission to captive or wild birds, although the demonstrated susceptibility to infection and subsequent oropharyngeal shedding of infectious virus cannot rule out their involvement. While swabs and tissues from passerine birds may be less useful for surveillance as compared with well-recognized reservoirs, such as waterfowl (Stallknecht \& Shane, 1988), serology may provide clues to LPAIV epidemiology, especially in passerines within close proximity to captive poultry and game bird facilities. Homologous and heterologous immunity to AIV in birds could be an important determinant of seasonal transmission intensity, and is also pertinent where numerous HPAIV and LPAIV strains co-circulate. Future experimental infection studies of passerines with LPAIV, including strains of poultry-origin and poultryadapted viruses, would further expand the present knowledge on their role in AIV ecology, while passerines in nature should be monitored to better understand their involvement in natural transmission dynamics and potential contribution to genetic recombination events (Roy et al., 1983).

\section{Acknowledgements}

The authors thank the following NWRC colleagues: R. McLean, A. Franklin, H. Sullivan, A. Freifeld, C. Benz, G. Gathright, D. Gossett, and Animal Care personnel. They are grateful to N. Mooers, S. Werner, S. Tupper (NWCR), and G. Young (CDC) for helping trap and process birds, and to A. Quintana, H. Pecoraro, G. Landolt, and J. Achenbach (Colorado State University) for laboratory expertise. A. Franklin provided guidance in data analyses.

\section{References}

Al-Attar, M.Y., Danial, F.A. \& Al-Baroodi, S.Y. (2008). Detection of antibodies against avian influenza virus in wild pigeons and starlings. Journal of Animal and Veterinary Advances, 7, 448-449.

Alexander, D.J., Allan, W.H., Parsons, D.G. \& Parsons, G. (1978). The pathogenicity of four avian influenza viruses for fowls, turkeys and ducks. Research in Veterinary Science, 24, 242-247.

Amin, A., Shalaby, M.A. \& Imam, I.Z. (1980). Studies on influenza virus isolated from migrating birds in Egypt. Comparative Immunology, Microbiology \& Infectious Diseases, 3, 241-246.

Boudreault, A. \& LeComte, J. (1981). Isolation of avian influenza viruses from different avian species in Canada in 1978. Revue Canadienne de Biologie, 40, 139-145 [in French].

Boudreault, A., LeComte, J. \& Hinshaw, V.S. (1980). Antigenic characterization of influenza A viruses isolated from captured birds in Ontario, Quebec and the Maritimes during 1977. Revue Canadienne de Biologie, 39, 107-114 [in French].

Brown, J.D., Swayne, D.E., Cooper, R.J., Burns, R.E. \& Stallknecht, D.E. (2007). Persistence of H5 and H7 avian influenza viruses in water. Avian Diseases, 51, 285-289.

Burnham, K.P. \& Anderson, D.R. (2002). Model Selection and Multimodel Inference: A Practical Information-theoretic Approach 2nd edn (pp. 35-37). New York: Springer-Verlag.

Campitelli, L., Di Martino, A., Spagnolo, D., Smith, G.J.D., Di Trani, L., Facchini, M., et al. (2008). Molecular analysis of avian H7 influenza viruses circulating in Eurasia in 1999-2005: detection of multiple reassortant virus genotypes. Journal of General Virology, 89, $48-59$.

Costa, T.P., Brown, J.D., Howerth, E.W. \& Stallknecht, D.E. (2010). The effect of age on avian influenza viral shedding in mallards (Anas platyrhynchos). Avian Diseases, 54, 581-585.

Cross, G.M. (1986). The status of avian influenza in poultry in Australia. In Proceedings of the 2nd International Symposium on Avian Influenza (pp. 96-103). Atlanta, GA, USA.

Desvaux, S., Marx, N., Ong, S., Gaidet, N., Hunt, M., Manuguerra, J.-C., et al. (2009). Highly pathogenic avian influenza virus (H5N1) outbreak in captive wild birds and cats, Cambodia. Emerging Infectious Diseases, 15, 475-478.

Ellström, P., Jourdain, E., Gunnarsson, O., Waldenström, J. \& Olsen, B. (2009). The "human influenza receptor" Neu5Ac $\alpha 2,6 \mathrm{Gal}$ is expressed among different taxa of wild birds. Archives of Virology, 154, 15331537.

Feare, C.J. (1984). The Starling. Oxford, UK: Oxford University Press. Fereidouni, S.R., Grund, C., Häuslaigner, R., Lange, E., Wilking, H., Harder, T.C., et al. (2010). Dynamics of specific antibody responses induced in mallards after infection by or immunization with low pathogenicity avian influenza viruses. Avian Diseases, 54, 79-85.

Fereidouni, S.R., Starick, E., Beer, M., Wilking, H., Kalthoff, D., Grund, C., et al. (2009). Highly pathogenic avian influenza virus infection of mallards with homo- and heterosubtypic immunity induced by low pathogenic avian influenza viruses. PLoS One, 4, e6706.

Forrest, H.L., Kim, J.-K. \& Webster, G. (2010). Virus shedding and potential for interspecies waterborne transmission of highly pathogenic $\mathrm{H} 5 \mathrm{~N} 1$ influenza virus in sparrows and chickens. Journal of Virology, 84, 3718-3720. 
Fuller, T.L., Saatchi, S.S., Curd, E.E., Toffelmier, E., Thomassen, H.A., Buermann, W., et al. (2010). Mapping the risk of avian influenza in wild birds in the US. BMC Infectious Diseases, 10, 187.

Globig, A., Staubach, C., Beer, M., Köppen, U., Fiedler, W., Nieburg, M., et al. (2009). Epidemiological and ornithological aspects of outbreaks of highly pathogenic avian influenza virus H5N1 of Asian lineage in wild birds in Germany, 2006 and 2007. Transboundary and Emerging Diseases, 56, 57-72.

Gronesova, P., Kabat, P., Trnka, A. \& Betakova, T. (2008). Using nested RT-PCR analyses to determine the prevalence of avian influenza viruses in passerines in western Slovakia, during summer 2007. Scandinavian Journal of Infectious Diseases, 40, 954-957.

Hinshaw, V.S. \& Webster, R.G. (1982). The natural history of influenza A viruses. In A.S. Beare (Ed.). Basic and Applied Influenza Research (pp. 79-104). Boca Raton, FL: CRC Press, Inc.

Johnson, D.C., Maxfield, B.G. \& Moulthrop, J.I. (1977). Epidemiologic studies of the 1975 avian influenza outbreak in chickens in Alabama. Avian Diseases, 21, 167-177.

Jourdain, E., Gunnarsson, G., Wahlgren, J., Latorre-Margalef, N., Bröjer, C., Sahlin, S., et al. (2010). Influenza virus in a natural host, the mallard: experimental infection data. PLoS One, 5, e8935.

Kida, H., Yanagawa, R. \& Matsuoka, Y. (1980). Duck influenza lacking evidence of disease signs and immune response. Infection and Immunity, 30, 547-553.

Kwon, Y.-K., Joh, S.-J., Kim, M.-C., Lee, Y.-J., Choi, J.-G., Lee, E.-K., et al. (2005). Highly pathogenic avian influenza in magpies (Pica pica sericea) in South Korea. Journal of Wildlife Diseases, 41, 618-623.

Latorre-Margalef, N., Gunnarsson, G., Munster, V.J., Fouchier, R.A.M., Osterhaus, A.D.M.E., Elmberg, J., et al. (2009). Effects of influenza A virus infection on migrating mallard ducks. Proceedings of the Royal Society B: Biological Sciences, 276, 1029-1036.

Lipkind, M.A., Weisman, Y., Shihmanter, E. \& Shoham, D. (1979). The first isolation of animal influenza virus in Israel. The Veterinary Record, 105, 510-511.

Lu, H. \& Castro, A.E. (2004). Evaluation of the infectivity, length of infection, and immune response of a low-pathogenicity H7N2 avian influenza virus in specific-pathogen-free chickens. Avian Diseases, 48, 263-270.

Mase, M., Tsukamoto, K., Imada, T., Imai, K., Tanimura, N., Nakamura, K., et al. (2005). Characterization of H5N1 influenza A viruses isolated during the 2003-2004 influenza outbreaks in Japan. Virology, 332, 167-176.

Moon, H.J., Song, M.S., Cruz, D.J.M., Park, K.J., Pascua, P.N.Q., Lee, J.H., et al. (2010). Active reassortment of H9 influenza viruses between wild birds and live-poultry markets in Korea. Archives of Virology, 155, 229-241.

Mundt, E., Gay, L., Jones, L., Saavedra, G., Tompkins, S.M. \& Tripp, R.A. (2009). Replication and pathogenesis associated with H5N1, H5N2, and H5N3 low-pathogenic avian influenza virus infection in chickens and ducks. Archives of Virology, 154, 1241-1248.

Munster, V.J., Baas, C., Lexmond, P., Waldenstrom, J., Wallensten, A., Fransson, T., et al. (2007). Spatial, temporal, and species variation in prevalence of influenza A viruses in wild migratory birds. PLoS Pathogens, 3, e61.

Nestorowicz, A., Kawaoka, Y., Bean, W.J. \& Webster, R.G. (1987). Molecular analysis of the hemagglutinin genes of Australian H7N7 influenza viruses: role of passerines birds in maintenance or transmission? Virology, 160, 411-418.

Olsen, B., Muster, V.J., Wallensten, A., Waldenstrom, J., Osterhaus, A.D.M.E. \& Fouchier, R.A.M. (2006). Global patterns of influenza A virus in wild birds. Science, 312, 384-388.
Pasick, J., Berhane, Y., Kehler, H., Hisanaga, T., Handel, K., Robinson, J., et al. (2010). Survey of influenza A viruses circulating in wild birds in Canada 2005 to 2007. Avian Diseases, 54, 440-445.

Peterson, A.T., Bush, S.E., Spackman, E., Swayne, D.E. \& Ip, H.S. (2008). Influenza A virus infections in land birds, People's Republic of China. Emerging Infectious Diseases, 14, 1644-1646.

Reed, L.J. \& Muench, H. (1938). A simple method of estimating fifty per cent endpoints. American Journal of Epidemiology, 27, 493-497.

Romváry, J., Meszaros, J., Tanyi, J., Rozsa, J. \& Fabian, L. (1976). Spreading of virus infection among wild birds and monkeys during the influenza epidemic caused by the Victoria (3) 75 variant of a H3N2 virus. Acta Veterinaria Academiae Scientiarum Hungaricae, 26, 369-376.

Roy, G., Burton, J., Lecomte, J. \& Boudreault, A. (1983). Role of passerine birds in the ecology of influenza viruses. Revue Canadienne de Biologie Expérimentale, 42, 73-81.

Slemons, R.D., Shieldcastle, M.C., Heyman, L.D., Bednarik, K.E. \& Senne, D.A. (1991). Type A influenza viruses in waterfowl in Ohio and implications for domestic turkeys. Avian Diseases, 35, 165-173.

Spackman, E., Pantin-Jackwood, M.J., Swayne, D.E. \& Suarez, D.L. (2009). An evaluation of avian influenza diagnostic methods with domestic duck specimens. Avian Diseases, 53, 276-280.

Spackman, E., Senne, D.A., Myers, T.J., Bulaga, L.L., Garber, L.P., Perdue, M.L., et al. (2002). Development of a real-time reverse transcriptase PCR assay for type A influenza virus and the avian H5 and $\mathrm{H} 7$ hemagglutinin subtypes. Journal of Clinical Microbiology, 40, 3256-3260.

Spickler, A.R., Trampel, D.W. \& Roth, J.A. (2008). The onset of virus shedding and clinical signs in chickens infected with high-pathogenicity and low-pathogenicity avian influenza viruses. Avian Pathology, 37, 555-577.

Stallknecht, D.E. \& Shane, S.M. (1988). Host range of avian influenza virus in free-living birds. Veterinary Research Communications, 12, $125-141$

Stallknecht, D.E., Shane, S.M., Kearney, M.T. \& Zwank, P.J. (1990a). Persistence of avian influenza viruses in water. Avian Diseases, 34, 406-411.

Stallknecht, D.E., Shane, S.M., Zwank, P.J., Senne, D.A. \& Kearney, M.T. (1990b). Avian influenza viruses from migratory and resident ducks of coastal Louisiana. Avian Diseases, 34, 398-405.

Sullivan, H.J., Blitvich, B.J., VanDalen, K., Bentler, K.T., Franklin, A.B. \& Root, J.J. (2009). Evaluation of an epitope-blocking enzymelinked immunosorbent assay for the detection of antibodies to influenza A virus in domestic and wild avian and mammalian species. Journal of Virological Methods, 161, 141-146.

Tang, Y., Wu, P., Peng, D., Wang, X., Wan, H., Zhang, P., et al. (2009). Characterization of duck H5N1 influenza viruses with differing pathogenicity in mallard (Anas platyrhynchos) ducks. Avian Pathology, 38, 457-467.

van der Goot, J.A., de Jong, M.C.M., Koch, G. \& van Boven, M. (2003). Comparison of the transmission characteristics of low and high pathogenicity avian influenza A virus (H5N2). Epidemiology and Infection, 131, 1003-1013.

Webster, R.G., Bean, W.J., Gorman, O.T. \& Chambers, T.M. (1992). Evolution and ecology of influenza A viruses. Microbiological Reviews, 56, 152-179.

Wing, L. (1943). Spread of the starling and English sparrow. The Auk, 60, 74-87.

Woolcock, P.R. (2008). Avian influenza virus isolation and propagation in chicken eggs. In E. Spackman (Ed.). Methods in Molecular Biology Vol. 436: Avian Influenza Virus (pp. 35-46). Totowa, NJ: Humana Press. 